\title{
The effect of short time post-weld heat treatment on the fatigue crack growth of 2205 duplex stainless steel welds
}

\author{
M.C. Young ${ }^{\mathrm{a}, 1}$, L.W. Tsay ${ }^{\mathrm{b}, *}$, C.-S. Shin ${ }^{\mathrm{c}}$, S.L.I. Chan ${ }^{\mathrm{d}}$ \\ ${ }^{a}$ Institute of Nuclear Energy Research, Division of Nuclear Fuels and Materials, Lungtan, Taoyuan 325, Taiwan, ROC \\ ${ }^{\mathrm{b}}$ Institute of Materials Engineering, National Taiwan Ocean University, Keelung 202, Taiwan, ROC \\ ${ }^{\mathrm{c}}$ Department of Mechanical Engineering, National Taiwan University, Taipei 106, Taiwan, ROC \\ d Institute of Materials Engineering, National Taiwan University, Taipei 106, Taiwan, ROC
}

Received 18 May 2006; received in revised form 11 January 2007; accepted 14 January 2007

Available online 24 January 2007

\begin{abstract}
The influence of $\gamma$ content and its morphology on the impact and fatigue crack growth behavior of 2205 duplex stainless steel (DSS) welds were studied in this work. Short time post-heating was able to effectively raise the $\gamma$ content and the impact toughness of the weld. The variation in microstructures showed less influence on the fatigue crack growth rate (FCGR) of the steel plate and weld except in the low $\Delta K$ regime. In contrast, residual welding stresses played a more significant affection on the FCGR of the DSS weld than microstructural factors did. Plastic deformation induced martensitic transformation within a definitely thin layer was responsible for the difference in crack growth behavior between specimens in the low $\Delta K$ range. Coarse columnar structure was more likely to have tortuous crack path in comparison with the steel plate.
\end{abstract}

(C) 2007 Elsevier Ltd. All rights reserved.

Keywords: Duplex stainless steel; Laser welding; Fatigue crack growth rate; Charpy impact; Post-heat treatment

\section{Introduction}

DSSs (2205 duplex stainless steels) consist of comparable amounts of ferritic $(\alpha)$ and austenitic phases $(\gamma)$. This gives the DSS the superior strength and stress-corrosion cracking resistance of ferritic stainless steels, as well as good ductility and toughness of austenitic stainless steels $[1,2]$. With these excellent properties, DSSs are used increasingly in chemical industries such as pressure vessels, heat exchangers and line-pipes. DSSs are highly anisotropic because of the elongated $\gamma$ phases embedded in the $\alpha$ matrix [3]. As shown in the previous work [4], the anisotropy had

\footnotetext{
* Corresponding author. Tel.: +886 2 24622192x6417; fax: +886 2 24625324

E-mail addresses: b0186@mail.ntou.edu.tw (L.W. Tsay), csshin@ntu. edu.tw (C.-S. Shin).

${ }^{1}$ Fax: +88634711409
}

little influence on the fatigue crack growth rate (FCGR) of 2205 DSS in air.

Modern DSSs have good weldability and can be welded by conventional welding processes under careful control of heat input to ensure a correct $\alpha / \gamma$ ratio in the weld [5]. Preheat and post-weld heat treatments of a DSS weld are in general not recommended [5]. Laser welding process offers many advantages over conventional arc welding process. However, the low-energy processes accompanying with fast cooling rates produce welds with higher $\alpha$ contents, which is responsible for its poor impact toughness [6,7]. As a result, the electron beam and laser beam welding processes are not recommended for joining DSS welds [8].

To alter the unbalanced $\alpha / \gamma$ ratio in the fusion zone and HAZ of a DSS laser weld, laser surface treatment is used to restore the correct $\alpha / \gamma$ ratio [9]. An addition of little amount of nickel powder [10] or assist-charging of nitrogen into the fusion zone during laser welding [11], may restore the correct $\alpha / \gamma$ ratio. According to the literature survey, 
little investigation has been carried out on the fatigue crack growth behavior of a DSS laser weld. In this study, short time post-weld heat treatments were performed after welding to increase the $\gamma$ content in the fusion zone of a 2205 DSS weld. The effects of $\gamma$ content and its morphology on the impact and fatigue behavior of the DSS weld metal were evaluated. A magnetic technique and quantitative image analysis were used to determine the $\alpha / \gamma$ ratios of the base plate and weld metal. Fatigue- and impact-tested specimens were examined by scanning electron microscopy (SEM) to identify fracture features, which were further correlated with their properties accordingly.

\section{Material and experimental procedures}

The chemical composition of the 2205 DSS plate in weight percent was $21.1 \mathrm{Cr}, 5.8 \mathrm{Ni}, 2.7 \mathrm{Mo}, 0.052 \mathrm{C}, 1.42$ $\mathrm{Mn}, 0.45 \mathrm{Si}, 0.025 \mathrm{P}, 0.022 \mathrm{~S}, 0.02 \mathrm{Cu}, 0.165 \mathrm{~N}$ and balance Fe. Laser welding was performed on the as-received $5 \mathrm{~mm}$ thick DSS plate, using a Rofin-Sinar $5 \mathrm{KW} \mathrm{CO}$ laser integrated with a computer-controlled working table. Laser welding parameters used in this work are listed in Table 1.

Fig. 1 is the schematic diagram showing Charpy impact and compact tension (CT) specimens sectioned from the laser-welded steel plate. The relative direction between crack growth and rolling direction (RD), named according to the ASTM E399 specification, is also indicated in Fig. 1. Both fatigue crack growth and impact tests were carried out at room temperature in laboratory air. The fatigue crack growth tests were conducted on an MTS 810 model servo-hydraulic testing machine under a constant amplitude sinusoidal loading. Fatigue data were analyzed using the MTS 790.40 fatigue crack growth software. The load ratio was set at 0.1 throughout the test. The crack length was determined by a compliance method [12] and confirmed by a traveling microscope at 30x magnification. The welded CT specimen was designated as $\mathrm{CW}$ when the fatigue crack propagated along the weld metal, as shown in Fig. 1. The stress intensity factor corresponding to the crack opening stress $\left(K_{\mathrm{op}}\right)$ was measured by compliance method using crack mouth clip gage. The degree of crack closure, $U$, was defined as the fraction of the load range for which the crack is open, $U=\Delta K_{\text {eff }} / \Delta K$.

Austensite is known to be the stable phase in the temperature range from $900{ }^{\circ} \mathrm{C}$ to $1100{ }^{\circ} \mathrm{C}$ [1]. Therefore, a high $\alpha$ content resulting from the high cooling rates in the as-welded (AW) DSS laser weld, or unbalanced phase ratio in the steel

Table 1

Laser welding parameters used in the experiment

\begin{tabular}{ll}
\hline Laser power & $3700 \mathrm{~W}$ \\
Travel speed & $600 \mathrm{~mm} / \mathrm{min}$ \\
Focal lens & $\mathrm{Cu}$ mirrior \\
Focal length & $200 \mathrm{~mm}$ \\
Focal point & $0.5 \mathrm{~mm}$ below the surface \\
Plasma-assisted gas flow rate $(\mathrm{He})$ & $30 \mathrm{~L} / \mathrm{min}$ \\
Shielding gas flow rate $(\mathrm{Ar})$ & $15 \mathrm{~L} / \mathrm{min}$ \\
Backing gas flow rate $(\mathrm{Ar})$ & $10 \mathrm{~L} / \mathrm{min}$ \\
\hline
\end{tabular}

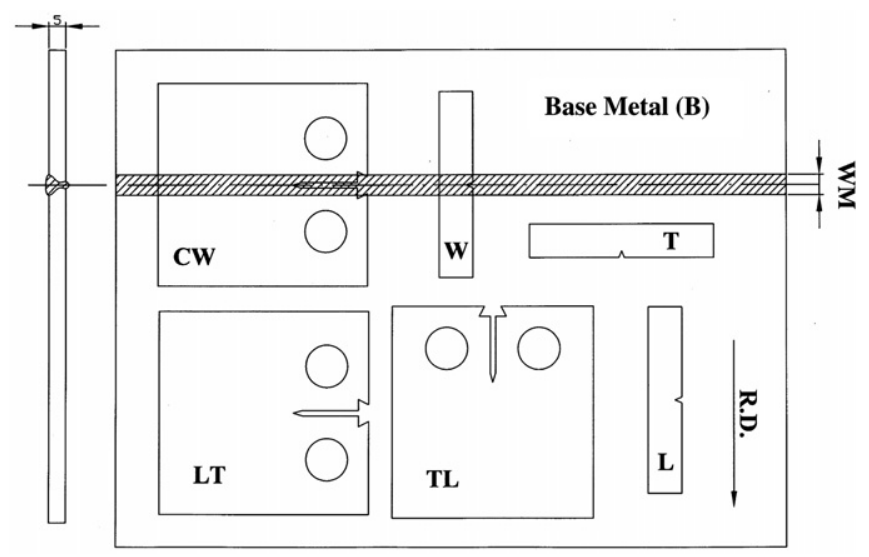

Fig. 1. The schematic diagram showing Charpy impact and compact tension specimens sectioned from the laser-welded steel plate.

plate, can be corrected by a proper heat treatment. In this work, post-heat treatment was carried out at $1050^{\circ} \mathrm{Cover}$ different periods of time from 15 to $60 \mathrm{~min}$, followed by cooling in air to raise the $\gamma$ content of the material. High soaking temperature not only restore the correct $\alpha / \gamma$ ratio but also help to release welding residual stresses. Welding residual stresses were determined by the modified hole-drilling strain gage method according to the specification of ASTM E83792. Similar experimental procedures had been conducted in previous studies for the determination of residual stresses $[13,14]$. The soaking time in minute was indicated as a number appending the specimen designation. For example, W15 or W60 indicates that the post-heating time was 15 or $60 \mathrm{~min}$ for the weld, respectively.

Due to the existence of fine and irregular $\alpha$ in the fusion zone of the weld, the $\alpha / \gamma$ ratio as determined using traditional image analysis was hard to be conducted sometimes. A magnetic technique was used to assist the measurement of the $\alpha / \gamma$ ratio of the base plate and weld metal. The magnetic technique, by means of the Ferrite scope, registered an average volume content of ferromagnetic phases present in the examined region. Murukami reagent was used to reveal the microstructures of the specimens; $\alpha$ phase appeared in gray and $\gamma$ was white in the metallograph. Fatigue fracture surface was examined by a Hitachi S4100 SEM, with attention being paid to the changes in fracture features. Fracture surface roughness and profile were measured by the height of the irregularities with respect to an average level. $R_{\mathrm{a}}$ is the arithmetic average of the absolute values of the roughness profile ordinates. Besides, $R_{\mathrm{z}}$ is the sum of the mean height of the five highest peak profiles and the mean depth of five deepest valley profiles measured from the mean line.

\section{Results and discussion}

\subsection{Microstructural observations}

Table 2 lists the $\alpha / \gamma$ ratio of various specimens measured by Ferrite scope. For the as-received base plate (B), the $\alpha / \gamma$ 
Table 2

The $\alpha / \gamma$ ratio of various specimens determined by Ferrite scope

\begin{tabular}{llllllll}
\hline Specimen & B & B60 & AW & AW15 & AW30 & AW45 & AW60 \\
\hline$\alpha / \gamma$ & $57 / 43 \pm 0.7$ & $40 / 60 \pm 0.7$ & $75 / 25 \pm 2.2$ & $53 / 47 \pm 2.0$ & $51 / 49 \pm 2.0$ & $47 / 53 \pm 1.7$ & $45 / 55 \pm 1.7$ \\
\hline
\end{tabular}

ratio fell within acceptable constitution (57/43). After one hour of soaking at $1050{ }^{\circ} \mathrm{C}$, the $\alpha / \gamma$ ratio of the steel plate was changed to $40 / 60$. This suggested that $\gamma$ content could be raised after suitable treatment. The high cooling rate associated with laser welding process resulted in the formation of excessive amount of $\alpha$ phase in the fusion zone $(\alpha / \gamma$ ratio $=75 / 25$ ). This unbalanced $\alpha / \gamma$ ratio was partly attributed to the reduced nitrogen content in the fusion zone as compared with the base plate [11]. The high $\alpha$ content in the as-welded laser weld would lead to a high susceptibility to hydrogen embrittlement $[10,11]$. The $\alpha / \gamma$ ratio was reduced with increasing soaking time, as listed in Table 2. It was noted that the $\alpha / \gamma$ ratio of the weld could be restored to the acceptable level by post-heating for as short as 15 min. Similar concepts regarding short time post-weld treatments have been introduced by subjecting the DSS weld to laser surface treatment [5]. Prolonged heating could further raise the $\gamma$ content, but at a decreasing rate.

Fig. 2 compares the microstructures of the steel plate and laser weld before and after $1050{ }^{\circ} \mathrm{C}$ post-heat treatment. For the steel plate, a severely elongated band structure still prevailed in spite of soaking at $1050{ }^{\circ} \mathrm{C}$ for $60 \mathrm{~min}$. This indicated that the $\alpha / \gamma$ banded structure was hard to be eliminated by the conventional heat treatment. Moreover, the steel plate after $1050^{\circ} \mathrm{C} / 60 \mathrm{~min}$ treatment consisted of coarser and greater amount of austenite as compared with the as-received steel plate. In contrast, the microstructures of the fusion zone were more irregular in morphologies. Little grain boundary $\gamma$ and its side plate together with some $\gamma$ precipitating intragranularly within the $\alpha$ matrix were observed in the as-welded weld (Fig. 2b). After a short time post-weld heat treatment, predominantly the precipitation of blocky $\gamma$ within the matrix (Fig. 2c) accounted for the great increase in the $\gamma$ content of the fusion zone, as listed in Table 2. With increasing soaking time, the $\gamma$ became coarser and greater but varied in a slower rate.

\subsection{Charpy impact test}

Charpy impact toughness of the steel plate and laser weld with/without $1050{ }^{\circ} \mathrm{C}$ post-heat treatments is listed in Table 3. The orientation with respect to the rolling direction had a great influence on the impact toughness of the base plate. Continuous tearing of the banded structure in the $\mathrm{T}$ specimen in contrast to the presence of the crack absorber $(\gamma)$ in the $\mathrm{L}$ specimen accounted for the lower impact toughness of the former. The influence of specimen orientation on the impact toughness could be corroborated with previous observation that post-treatment did not remove the banded structure. Post-heated steel plate gave a considerably higher $\gamma$ content, but the impact energy was even lowered. The reasons could be partly attributed to coarse banded microstructures in the post-heated steel
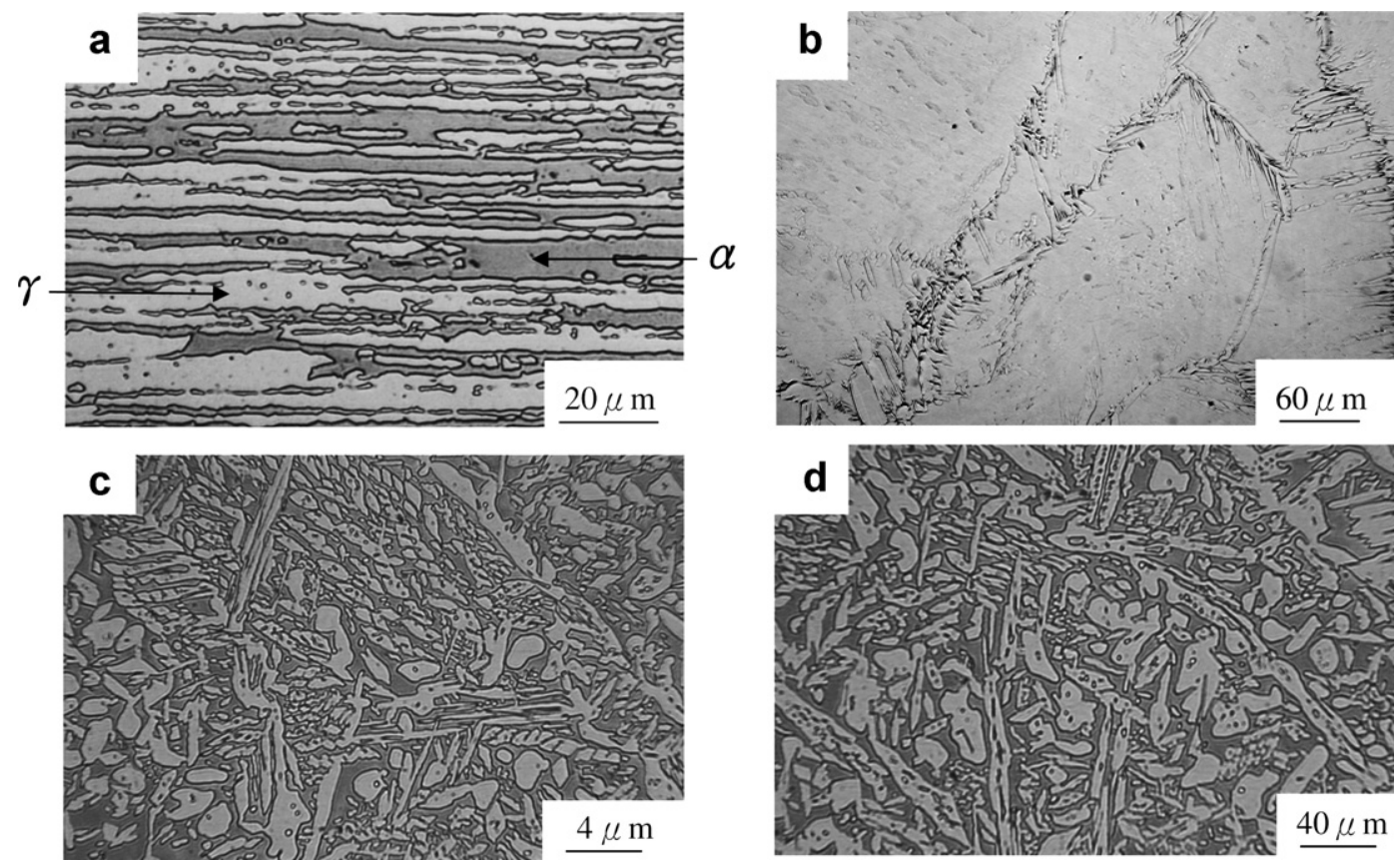

Fig. 2. Metallographs showing the microstructures of steel plate and laser weld in distinct conditions: (a) as-received steel plate, (b) AW, (c) AW15 and (d) AW60 specimens. 
Table 3

Charpy impact toughness of the steel plate and laser weld with/without $1050{ }^{\circ} \mathrm{C}$ post-heat treatments

\begin{tabular}{llllllll}
\hline Specimen & L & T & L60 & T60 & W & W15 & W60 \\
\hline Impact Energy (J) & 143 & 90 & 110 & 88 & 95 & 136 & 144 \\
\hline
\end{tabular}

plate. In contrast, the great increase in $\gamma$ content and change in $\gamma$ morphology in the post-heated fusion zone was responsible for the improved weld's impact toughness, even after short time post-weld heat treatment. Fig. 3 shows the impact-fractured appearance of various specimens. The steel plates with the banded structure all revealed ductile dimple fracture after SEM examinations (Fig. 3a). In case of the as-welded weld, the presence of fine facet mixed with small dimple fracture might be attributed to the inherently low $\gamma$ content (Fig. 3b). Extensively $\gamma$ precipitation in the granular and island forms within the matrix accounted for the great increase in impact energy, and the presence of numerous fine dimples in the postheated welds (Fig. 3c).

\subsection{Fatigue crack growth test}

The fatigue crack growth behaviors of DSS steel plate and laser weld tested in laboratory air are shown in Fig. 4. The measured FCGR in the DSS was the result of the overall crack growth rate contributed by $\gamma$ and $\alpha$ phases simultaneously. The TL and LT specimens exhibited the same fatigue crack growth behavior, as shown in Fig. 4a. As mentioned previously, the specimen orientation had a great influence on the impact energy but its effect on FCGR of the as-received steel was minor. This meant that the impact energy could not be used as an indicator to anticipate the crack growth behavior of the DSS. Besides, raising the $\gamma$ content by post-heating the steel plate (i.e. TL60 and LT60 specimens) could only reduce the FCGR of the alloy slightly in the low $\Delta K$ regime (Fig. 4a). Therefore, it seemed that the variation of $\gamma$ content and morphology within certain realm had limited effects on the FCGR of this alloy.

For the as-welded weld $(\mathrm{CW})$, the FCGR increased significantly with increasing $\Delta K$ (Fig. $4 \mathrm{~b}$. Also, the fatigue threshold of the CW specimen was clearly higher than that of the other specimens. The measurements of residual stresses in the as-welded fusion zone indicated that principal residual stresses were with the magnitude of $348 \mathrm{MPa}$ in the direction parallel to the welding direction (longitudinal direction) and $47 \mathrm{MPa}$ transverse to it. After post-weld heat treatment for $30 \mathrm{~min}$, residual stresses in the fusion zone were reduced to $122 \mathrm{MPa}$ in the longitudinal direction and $-57 \mathrm{MPa}$ in the transverse direction. The presence of tensile residual stresses in both directions within the aswelded fusion zone was found not to accelerate the crack growth. Similar results also point out that the FCGRs in the fusion zone and the heat-affected zone are lower than that of the base metal for the as-welded A514 weld [15]. Reduced FCGR in the fusion zone of a weld can be attrib-
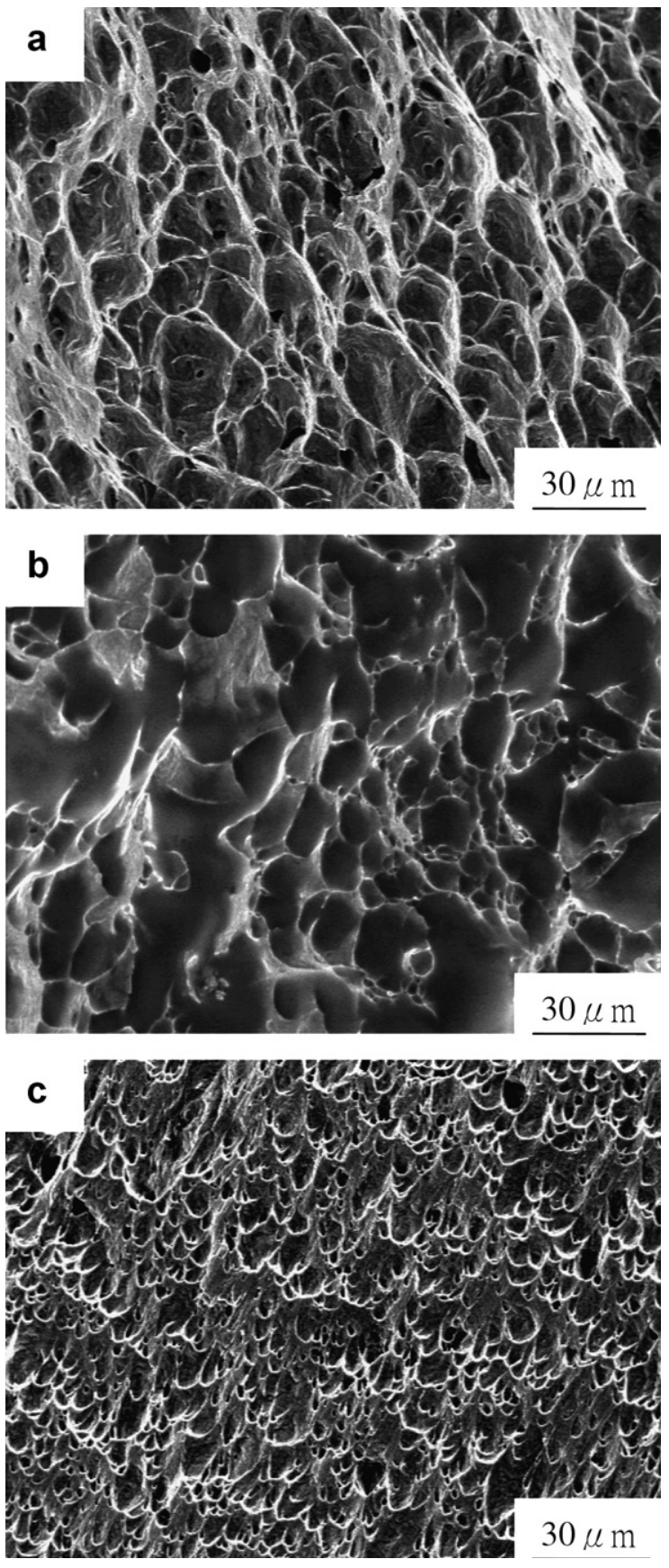

Fig. 3. Impact fracture appearance of the (a) L, (b) W and (c) W60 specimens after SEM examinations.

uted to the redistribution of residual stresses after introducing a fatigue crack into the weld metal [16]. The residual stress field in the as-welded weld tends to bend and rotate the crack face, leading to crack closure and resulting in the reduced FCGR [16]. In previous study [17], the induced compressive residual stresses ahead of crack front can obviously retard the crack growth of laser-treated 304 SS as the crack grows in the direction normal to the laser scan direction. Moreover, after stress relief heat treatment the weld is reported to exhibit a considerable increase in FCGR as compared with the as-welded weld [15]. It could be the 

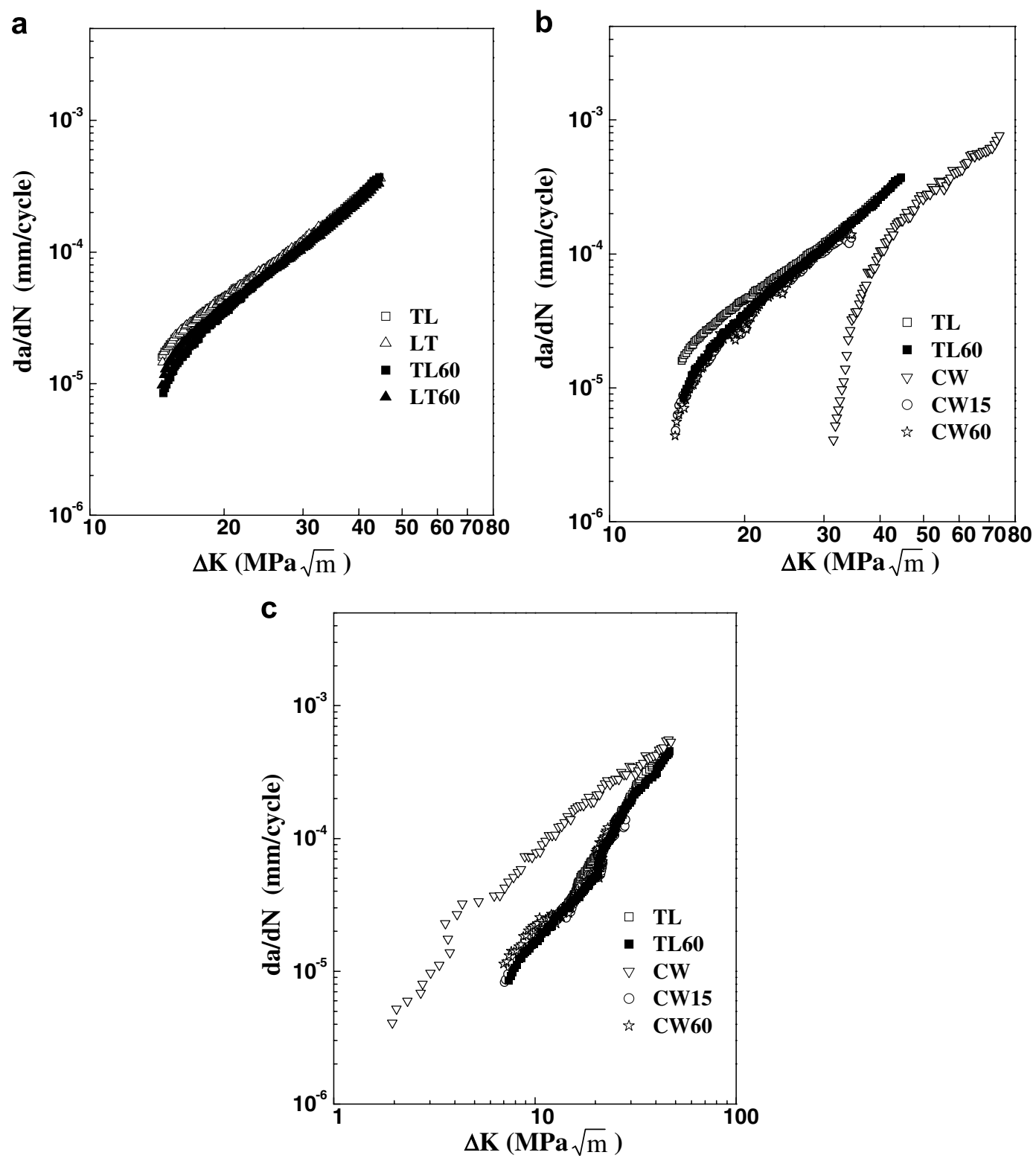

Fig. 4. The fatigue crack growth behaviors of DSS steel plate and laser weld tested in laboratory air.

residual stresses in the post-heated welds, even for the weld heated at $1050{ }^{\circ} \mathrm{C}$ for as short as $15 \mathrm{~min}$, were lower enough hence did not cause an obvious crack closure. Therefore, the initially high resistance to crack growth disappeared in the low $\Delta K$ region. In this work, residual welding stresses showed a more significant effect on the FCGR of the DSS weld than the microstructural factors did. The post-heated welds (CW15 \& CW60) and steel plates (TL \& TL60) had quite different microstructures and impact energies, yet their fatigue crack growth characteristics were similar to each other, as shown in Fig. 4b.

When da/dN was represented in term of $\Delta K_{\text {eff }}$ (Fig. $4 \mathrm{c}$ ), the difference in FCGR between various specimens was reduced. It was worth mentioning that $\mathrm{CW}$ specimen behaved the highest FCGR among the specimens. In fact, the use of crack closure did not completely reflect the crack growth behavior of the $\mathrm{CW}$ specimen. Fig. 5 shows the degree of crack closure in various specimens. The $U$ value of $\mathrm{CW}$ specimen was obviously lower than other specimens, resulting in a high resistance to crack growth. In comparison with the TL specimen, all post-heated specimens, including the steel plate and welds, had slightly smaller $U$ values, especially in the low $\Delta K$ range. The initial distinction in $U$ value between post-heated and TL specimens led to a difference in FCGR between them. The results also indicated that the crack opening level of postheated specimens increased rapidly with increasing $\Delta K$ range, and finally reached the level of the TL specimen.

\subsection{X-ray diffraction}

The strain-induced martensite has been shown to influence the fatigue crack growth behavior of metastable stainless steels [18-21]. Such transformation will 


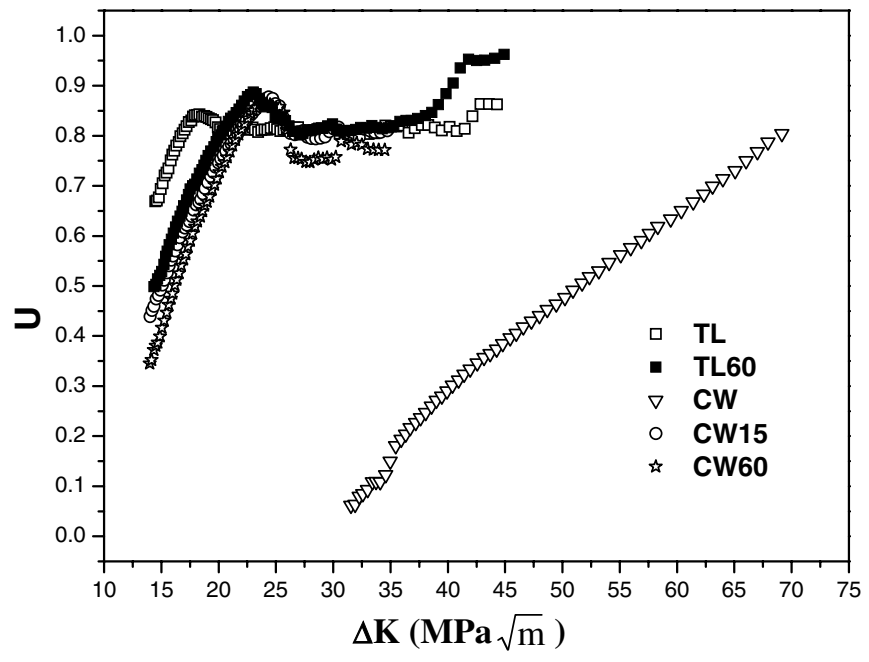

Fig. 5. The development of crack closure in distinct specimens.

contribute to premature fatigue crack closure. Fig. 6 is the $\mathrm{X}$-ray diffraction pattern of various specimens measured on the fatigue-fractured surface in comparison with the counterpart specimen. The induced martensite formed on the crack surface was related to the varied $\alpha / \gamma$ ratio. As shown in Fig. 6a, the as-received steel plate (B) consisted of nearly balanced $\alpha / \gamma$ ratio (57/43). Moreover, the $\alpha / \gamma$ ratio changed to about $70 / 30$ on the fatigue-fractured surface of TL specimen. The increased $\alpha$ content actually revealed that a small portion of $\gamma$ did transform to martensite as a result of cyclic straining. When approximately $20 \mu \mathrm{m}$ of the material on the fatigue-fractured surface was removed, X-ray diffraction pattern (TL-20 $\mu \mathrm{m})$ showed less fraction of ferromagnetic phases present at this depth. At a depth of about $60 \mu \mathrm{m}(\mathrm{TL}-60 \mu \mathrm{m})$ below the crack surface, the $\alpha / \gamma$ ratio reversed to that of the steel plate (B). Therefore, the results indicated that a small portion of austenite had transformed to martensite within a definite depth below the crack surface.

The ease of $\gamma$ to $\alpha$ transformation depends on the $\gamma$ stability, imposed strain and working temperature, etc. A lesser austenite stabilizer within the $\gamma$ phase resulted in a higher ability of it to undergo martensitic transformation. As listed in Table 2, B60 specimens consisted of a greater $\gamma$ content than the B. Therefore, the $\gamma$ in the former was more likely to undergo transformation than that of the latter after cyclic straining, owing to the lean of $\gamma$ stabilizer in the former. As shown in Fig. 6b, it was noted that about $24 \%$ increase in $\alpha$ content in the B60 specimen, in contrast to $13 \%$ in the B. The post-treated weld also showed the trend of strain-induced transformation as the steel plate. It was deduced that such a phase transformation within a thin layer enhanced the crack closure, and accounted for the difference in crack growth behavior between TL and post-treated specimens (TL60, CW60) in the low $\Delta K$ range. Such a thin layer of transformation was anticipated to reduce its influence on the FCGR at the high $\Delta K$ range or large crack opening level.
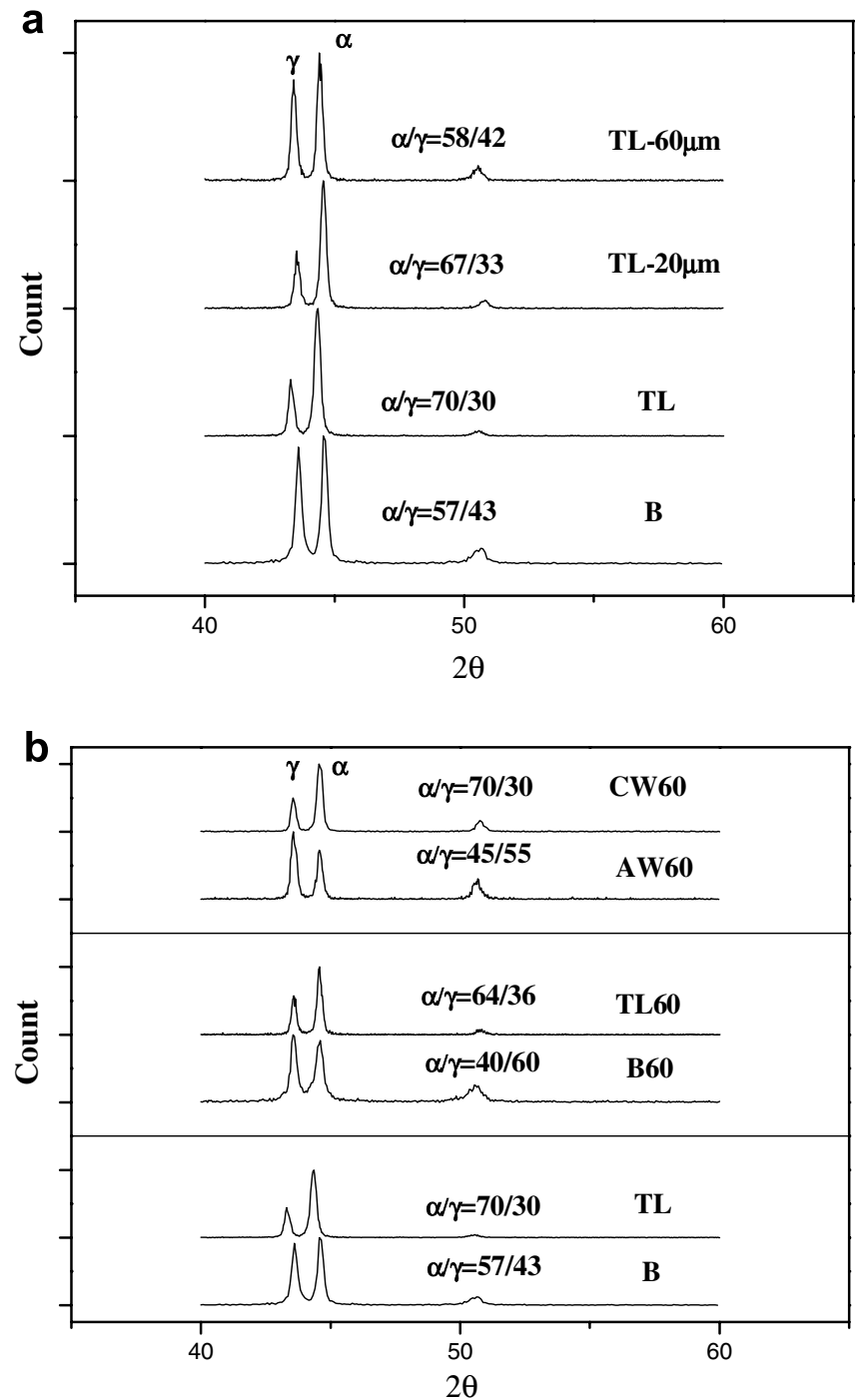

Fig. 6. The comparison of $\alpha / \gamma$ ratio related to the increased amount of strain-induced martensite formed on the fatigue-fractured surface determined by X-ray diffraction, (a) the patterns of the fatigued TL specimen measured at different depths below the fracture surface in comparison with the base plate (B) and (b) the $\alpha / \gamma$ ratio found on the fatigue-fracture surface of the specimens as compared with the original constituent of the corresponding specimens.

\subsection{Fractographs}

Fig. 7 shows the typical macroscopic fatigue-fractured appearance of the specimens as well as the corresponding fracture surface roughness. The results revealed that the fracture surface of post-heated welds (Fig. 7a) was much rougher and irregular in comparison with that of the steel plate (Fig. 7b) over the entire surface. The rough appearance of CW60 specimens could be attributed to the inherently coarse solidified structure in the fusion zone. Such a coarse structure was more likely to have a deflected crack path, leading to a slightly higher crack closure [22-24]. The variation of surface roughness and amplitude (Fig. 7c) confirmed such evidences. Therefore, the CW 60 specimen with a zig-zag crack path behaved a lower FCGR than the base plate, especially in the low $\Delta K$ range. 

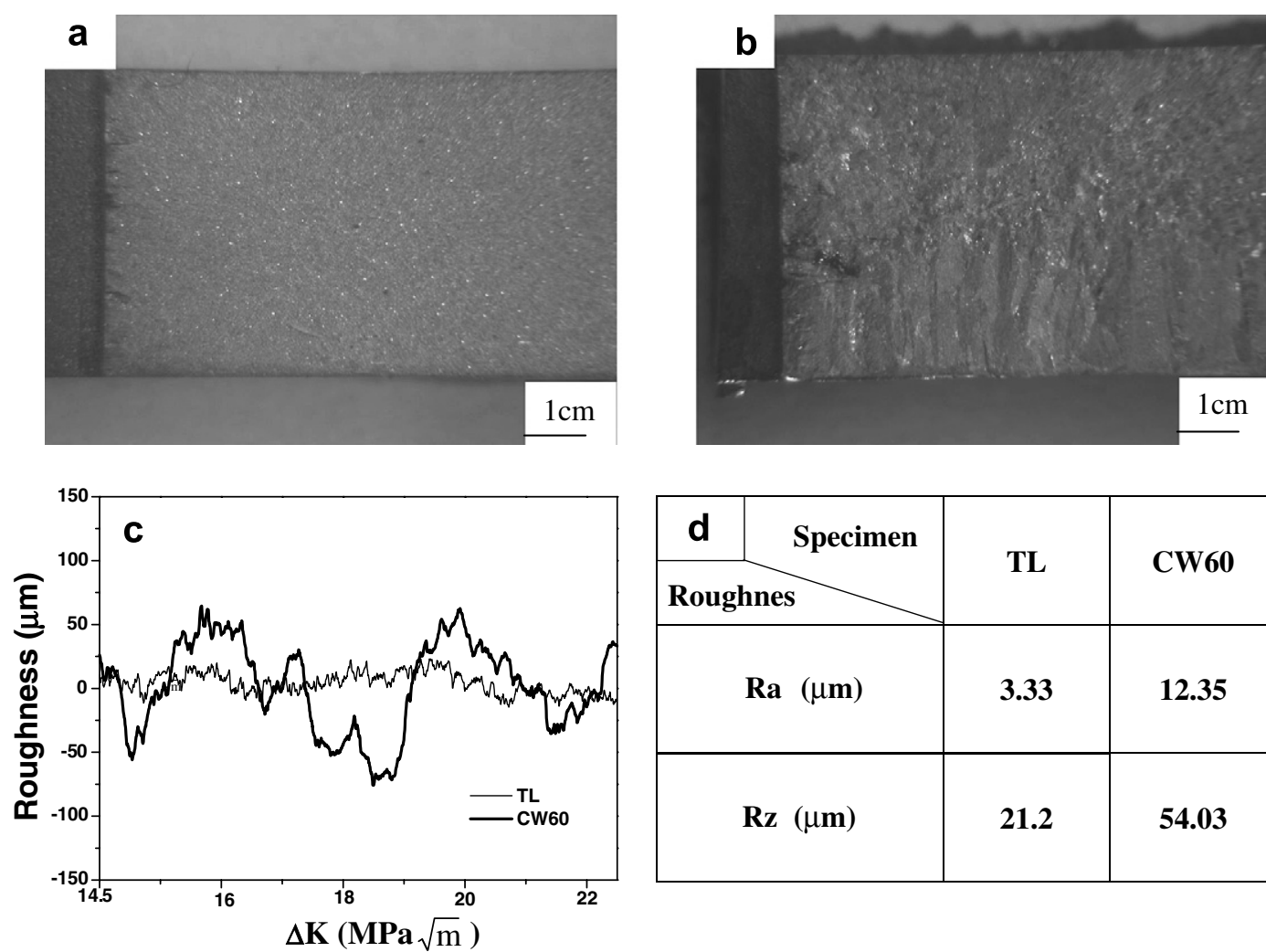

\begin{tabular}{|c|c|c|}
\hline \begin{tabular}{c|r} 
d & Specimen \\
Roughnes
\end{tabular} & $\mathbf{T L}$ & CW60 \\
\hline $\mathbf{R a}(\mu \mathbf{m})$ & 3.33 & 12.35 \\
\hline $\mathbf{R z}(\mu \mathbf{m})$ & 21.2 & 54.03 \\
\hline
\end{tabular}

Fig. 7. The typically macroscopic fatigue-fractured appearance of (a) steel plate, (b) $1050{ }^{\circ} \mathrm{C} / 60$ min post-heated weld, (c) the variation of surface roughness in corresponding specimens and (d) the Ra and Rz values of the specimens.
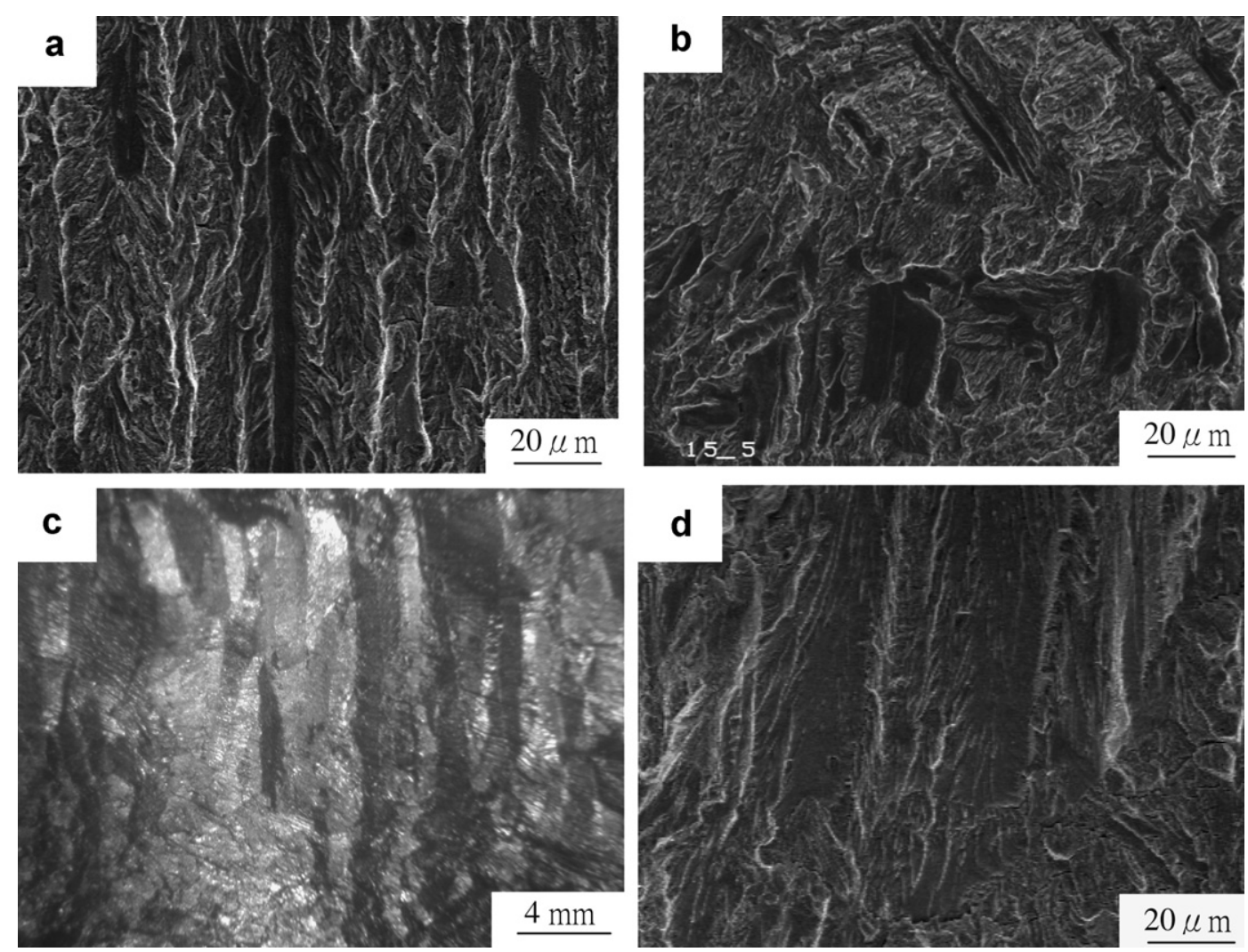

Fig. 8. SEM fracture features of various specimens, (a) steel plate, (b) CW60, (c) macroscopic fracture feature of CW and (d) detailed morphology of CW specimens. 
Fig. 8 shows the fracture appearance of various specimens. Fracture appearance of the base plate consisted of mainly transgranular fatigue fracture and small amount of elongated faceted failure (Fig. 8a). The aspect and shape of faceted flats were inter-dispersed on fracture surface of the laser-welded specimens (Fig. 8b). Moreover, the extent of flat fracture was wider for the weld relative to the base plate. In previous researches [25], the $\alpha / \gamma$ interface is the easy path for crack propagation. Therefore, acicular and blocky $\gamma$ inter-dispersed randomly in the fusion zone of DSS welds tended to exhibit disorder facet fracture as compared with the banded steel plate. It was deduced that the irregular separation of $\alpha / \gamma$ interface (Fig. 8b) contributed to the deflected crack growth, resulting in the formation of rougher surface in the CW60 specimen. It was noted that coarse columnar structures were seen on the macroscopic fracture appearance of $\mathrm{CW}$ specimen (Fig. 8c). Detailed examination showed brittle facet failure extensively (Fig. 8d). It was implied that the higher brittleness of $\mathrm{CW}$ specimens associated with abnormal high $\alpha$ content, accounted for the inherently higher FCGR relative to other specimens as shown in Fig. 4c.

\section{Conclusions}

(1) The $\alpha / \gamma$ ratio in the fusion zone of the as-welded weld was drastically increased as compared with the balanced steel plate. The short time post-weld treatment at $1050{ }^{\circ} \mathrm{C}$ could effectively restore the $\alpha / \gamma$ ratio of the fusion zone to comparable conditions. The great increase in $\gamma$ content and change in $\gamma$ morphology was responsible for the improved weld's impact toughness, even after short time post-weld heat treatment.

(2) Fatigue crack growth tests revealed that the variation of $\gamma$ content and morphology within certain realm had limited effects on the FCGR of the steel plates and welds. Residual welding stresses played a more significant affection on the FCGR of the DSS weld than microstructural factors did. Plastic deformation induced martensitic transformation within a thin layer caused the crack closure and accounted for the difference in crack growth behavior between the specimens, especially in the low $\Delta K$ range. Coarse columnar structure in the DSS weld was more likely to have a tortuous crack path over the entire $\Delta K$ range in comparison with the steel plate.

\section{Acknowledgements}

The authors gratefully acknowledge the financial support of this study by National Science Council of Republic, China (NSC 92-2216-E-019-009).

\section{References}

[1] Nilsson JO. Mater Sci Technol 1992;8:685.

[2] Dupoiron F, Audouard JP. Scand J Metall 1996;25:95.

[3] Zheng W, Hardie D. Corrosion 1991;47:792.

[4] Tsay LW, Young MC, Shin C-S, Chan SLI. Fatigue Fract Eng Mater Struct [submitted for publication].

[5] Berglund G, Wilhelmsson P. Mater Des 1989;10:23.

[6] Ku JS, Ho NJ, Tjong SC. J Mater Process Technol 1997;63:770.

[7] Kordatos JD, Fourlaris G, Papadimitrious G. Scripta Mater 2001;44:401.

[8] Oates WR, Saitta AM, editors. Welding Handbook, 8th ed., Vol. 4. Maimi: AWS; 1996. p. 233.

[9] Capello E, Chiarello P, Previtali, Vedani M. Mater Sci Eng A 2003;351:334.

[10] Wu HC, Tsay LW, Chen C. ISIJ Inter 2004;44:1720.

[11] Young MC, Chan SLI, Tsay LW, Shin C-S. Mater Chem Phys 2005;91:21.

[12] Saxena A, Hudak SJ. Int J Fract 1978;14:453.

[13] Tsay LW, Lin HH, Shiue RK. Corr Sci 2004;46:2651.

[14] Tsay LW, Young MC, Chou FY, Shiue RK. Mater Chem Phys 2004;88:348.

[15] Parry M, Nordberg H, Hertzberg RW. Weld J 1972;51:485.

[16] Shi YW, Chen BY, Zhang JX. Eng Fract Mech 1990;36:893.

[17] Shiue RK, Chang CT, Young MC, Tsay LW. Mater Sci Eng A 2004;364:101.

[18] Schuster G, Altstetter C. Metall Trans 1983;14A:2077.

[19] Tsay LW, Young MC, Chen C. Corr Sci 2003;45:1985.

[20] Mei Z, Morris JW. Metall Trans 1990;21A:3137.

[21] Tsay LW, Liu YC, Lin D-Y, Young MC. Mater Sci Eng A 2004;384:177.

[22] Lanes L, Mateo A, Violan P, Méndez J, Anglada M. Mater Sci Eng A 1997;234-236:850.

[23] Kang TH, Li DM, Lee YD, Lee CS. Mater Sci Eng A 1998;251:192.

[24] Iturgoyen L, Anglada M. Fatigue Fract Eng Mater Struct 1997;20:917.

[25] Akdut N. Int J fatigue 1999;21:97. 